\title{
Optical properties of diamond-like carbon thin films deposited by DC-PECVD
}

\author{
Karim Deraman, Suriany Sarmid, Bakar Ismail, N.E. Ahmad, R. Hussin, W. Nurulhuda W. Shamsuri, \\ M. Nor M. Yusof and Khaidzir Hamzah \\ Phosphor Materials Research Group, Department of Physics, Universiti Teknologi Malaysia, 81310 UTM Skudai, Johor, Malaysia
}

Received 26 November 2010, Revised 26 December 2010, Accepted 4 Januari 2011, Available online 15 Januari 2011

\begin{abstract}
Diamond-like carbon (DLC) thin films were deposited at different substrate temperatures using methane gas in DC-PECVD at $1 \times 10^{-1}$ Torr. From the light transmission using UV-VIS spectroscopy it was found that the optical transition had changed from allowed indirect transition to forbidden direct transition as the substrate temperature increased. The photoluminescence study has shown that the recombination centre occurred at $1.738 \mathrm{eV}$. The observation in the present work shows that the Urbach energy decreases with increasing substrate temperature provides evidence that such films have a narrowed band tail. This decrease in Urbach energy is due to a more ordered structure with lower hydrogen concentration and larger cluster by the increase in the degree of cross-linking of the C-C network. Distorted cluster which contribute to the broadening of the band tail may also contribute to the PL peak width. As the substrate temperature increases, the cluster size in the tetrahedral hydrogenated amorphous carbon (ta-C:H) increases, resulting in smaller band gap and the structure is more ordered as the decrease in Urbach energy, give the decrease in PL peak energy.
\end{abstract}

| Diamond like carbon | DC-PECVD | Optical properties | Photoluminescence | Amorphous carbon |

(B) 2011 Ibnu Sina Institute. All rights reserved. http://dx.doi.org/10.11113/mjfas.v7n1.201

\section{INTRODUCTION}

The diamond thin films have received much attention as promising material due to their unique combination of desirable electrical, optical, and mechanical properties [1, 2] and many potential applications. Unfortunately, diamond films require high temperature $\left(\sim 800{ }^{\circ} \mathrm{C}\right)$ for their growth thereby limiting the choice of the substrate. The amorphous carbon $(\mathrm{a}-\mathrm{C})$ and amorphous carbon hydrogenated $(\mathrm{a}-\mathrm{C}: \mathrm{H})$ films called diamond-like carbon (DLC) retain most of the properties of diamond and can overcome the above mentioned limitations to a large extent.

Recently, there has been a lot of interest in developing DLC for sensors at higher temperatures and in harsh environment, where $\mathrm{Si}$ cannot be used. There is a significant interest in DLC because of their unique properties [3, 4]. DLC films are beginning to find their way into many industrial wear applications. Because of its high hardness, chemical inertness, optical transparency, and its wide band gap semiconductor, it has been use as protective coating in area such as for optical windows, antireflection coating for $\mathrm{Si}$ solar cell and protective coatings on copper mirror for automobile industry $[5,6,7]$.

In this paper the influence of the substrate temperature on some of the optical properties of DLC films deposited using DC-PECVD technique was presented. These films were deposited with different

Corresponding author at: Faculty of Science, Physics Department,

Universiti Teknologi Malaysia, Skudai, 81310 Skudai, Johor

E-mail addresses: bakar@dfiz2.fs.utm.my (Dr.Bakar Ismail) substrate temperatures between $25^{\circ} \mathrm{C}$ to $200^{\circ} \mathrm{C}$ keeping the other deposited parameters fixed at certain values.

\section{EXPERIMENTAL}

Diamond-like carbon films were deposited using the direct current plasma enhanced chemical vapour deposition (DC-PECVD) in $99.5 \%$ of methane gas. During all deposition, the distance between anode to substrate holder was kept at $4 \mathrm{~cm}$ while the gas pressure and flow were $1 \times 10^{-1}$ Torr and $9 \mathrm{sccm}$ respectively.

The heater used in DC-PECVD system was homemade in order to obtain high substrate temperature up to $600{ }^{\circ} \mathrm{C}$, using a Kantall wire as the heating element. The substrate temperature was measured by thermocouple. Corning glass substrates were placed on a $6.8 \mathrm{~cm}$ diameter stainless-steel cathode fed by a DC $(1.2 \mathrm{kV})$ power supply. All substrate were cleaned in chromic acid and deionised water.

The transmittance of the DLC thin films was performed using UV-Vis spectrophotometer model Lambda 25. The transmission scanning was obtained over a wavelength region of 300-1100 nm. The photoluminescence spectrometer used for the present study is model Luminescence LS55 (Perkin Elmer), DLC samples were excited with different wavelengths (240 to $800 \mathrm{~nm}$ ) with step of $20 \mathrm{~nm}$ to get the emission spectrum for different excitation energies. The excitation was done at fixed excitation slit, $4.0 \mathrm{~nm}$ and emission slit $3.5 \mathrm{~nm}$. 


\section{RESULTS \& DISCUSSION}

\subsection{Optical Band Gap $\left(E_{o p t}\right)$}

In order to determine the type of transition involve in the DLC thin films, the graph of $\ln \alpha$ versus $\ln h v$ is plotted as shown in Figure 1. Usually there are involved four different types of optical transition in DLC thin films; allowable direct transition, forbidden direct transition, allowable indirect transition and forbidden indirect transition, dependent on the gradient of the graph called index $\mathrm{r}$ and obey linear equation of $\alpha h v=\mathrm{B}\left(h v-E_{o p t}\right)^{\mathrm{r}}$, where $\alpha$ is the absorption coefficient, $h$ is Planck constant, $v$ is frequency, B is a constant and $E_{\text {opt }}$ is optical gap [8].

Figure 1 shows a similar trend and $\ln \alpha$ increases with increasing ln $h v$. The gradient values decrease with increasing substrate temperatures in the range 1.08 to 2.36 , which is between forbidden direct transition $(r=1.5)$ and allowable indirect transition $(r=2)$. The gradient values for $423,473,523$ and $573 \mathrm{~K}$ substrate temperature are 2.36 , $2.12,1.14$ and 1.08 , respectively. Therefore, the optical transition present in the hydrogenated tetrahedral amorphous carbon (ta-C:H) thin films deposited at different substrate temperature can be summarised as follows: (i) The ta-C:H films prepared at 423 and $473 \mathrm{~K}$ substrate temperature are having allowable indirect transition. (ii) The optical transition changes to forbidden direct transition as the substrate temperature increased to $523 \mathrm{~K}$ and $573 \mathrm{~K}$.

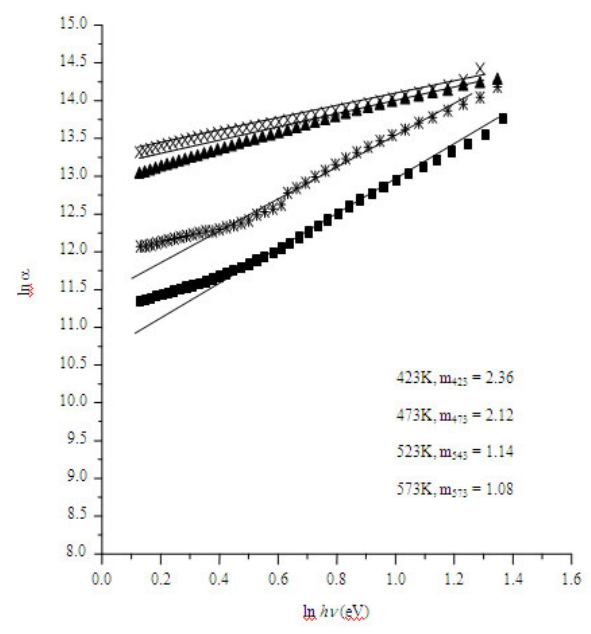

Figure 1 The graph of $\ln \alpha$ versus $\ln h v$

The optical band, $\left(E_{\text {opt }}\right)$ of the taC:H thin films can be obtained by projecting the vertical linear until it crosses the $x$-axis in graphs of $(\alpha h v)^{2 / 3}$ and $(\alpha h v)^{1 / 2}$ versus photon energy which are for forbidden direct transition and allowable indirect transition, respectively. The graph of forbidden direct transition and allowable indirect are shown in Figure 2 and 3, respectively. The optical transition (forbidden direct transition and allowable indirect) presence in ta-C:H thin films are listed in Table 1. The optical band gap for each sample is selected according to its type of optical transition and also listed in Table 1.

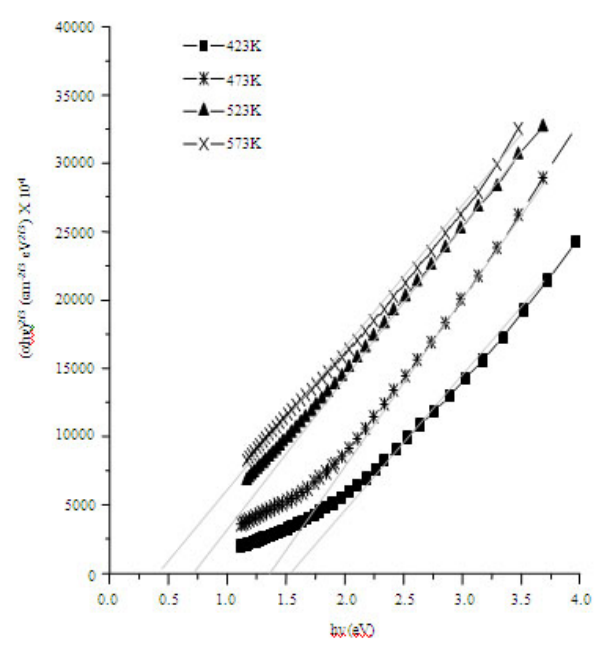

Figure 2: Graph $(\alpha h y)^{2 / 3}$ versus photon energy, $h y$ of the $\mathrm{taC} \cdot \mathrm{H}$ thin films deposited at different substrate temperatures.

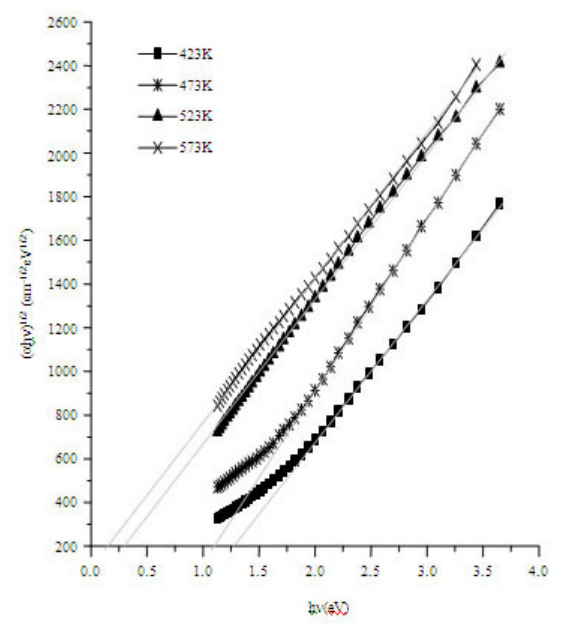

Figure 3: Graph $(\alpha h v)^{1 / 2}$ versus photon energy, $h w$ of the $\mathrm{taC} \cdot \mathrm{H}$ thin films deposited at different substrate temperatures.

The optical gap of the taC:H decreases with increasing substrate temperature as shown in Figure 4. This result is consistent with the result obtained by [9]. The optical gap varied in a range of 0.40 to $1.30 \mathrm{eV}$. Theoretical models for taC: $\mathrm{H}$ with a high $s p^{3}$ content to explain the optical gap is by predict that the nature of $s p^{2}$ - bonded atoms on the ta-C:H films. The band gap is determined by the configuration of $\pi$ states on the $s p^{2}$ site because their $\pi$ state lies closest to the Fermi level. As at 423 and $473 \mathrm{~K}$ substrate temperature, the optical band gap tends to decrease because of the increasing $\pi$ state. At higher substrate temperature where the $s p^{3}$ ratio starts to increase slightly before the main 
part of $\mathrm{H}$ evolution, the optical gap is greatly decreased. Once hydrogen is mobile, the $\mathrm{C}-\mathrm{C}$ network starts to rearrange and causes the optical gap to close up.

Table 1: The optical transition (forbidden direct transition, allowable indirect transition) and optical band gaps obtained from DLC thin films at different substrate temperature.

\begin{tabular}{cccc}
\hline $\begin{array}{c}\text { Substrate } \\
\text { Temperature } \\
(\mathbf{K})\end{array}$ & $\begin{array}{c}\text { Forbidden } \\
\text { Direct } \\
\text { Transition, } \\
\boldsymbol{E}_{\text {opt }}(\mathbf{e V})\end{array}$ & $\begin{array}{c}\text { Allowable } \\
\text { Indirect } \\
\text { Transition, } \\
\boldsymbol{E}_{\text {opt }}(\mathbf{e V})\end{array}$ & $\begin{array}{c}\text { Optical } \\
\text { band gap, } \\
\boldsymbol{E}_{\text {opt }}(\mathbf{e V})\end{array}$ \\
\hline 423 & 1.50 & 1.30 & 1.30 \\
473 & 1.35 & 1.10 & 1.10 \\
523 & 0.70 & 0.30 & 0.70 \\
573 & 0.40 & 0.15 & 0.40 \\
\hline
\end{tabular}

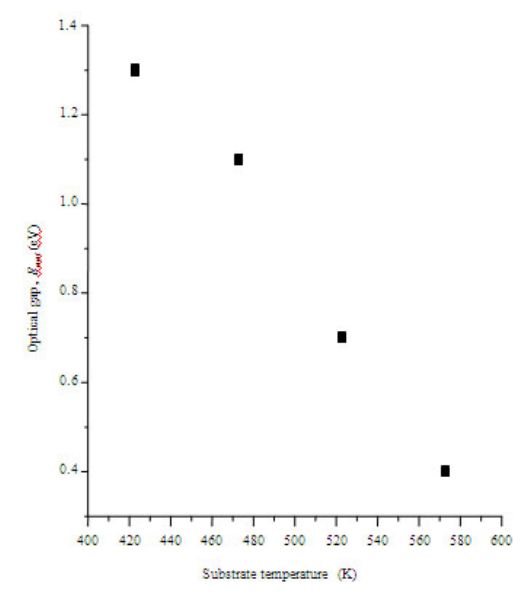

Figure 4: The optical gap, $E_{a x x}$ as a function of substrate temperature

A low substrate temperature $(423-473 \mathrm{~K})$ of the not really ta-C:H thin films that give high $E_{\text {opt }}$ value can be explained by the size of the $s p^{2}$ cluster. According to [10], the $E_{\text {opt }}$ is large in small cluster size and small in larger cluster size. When $s p^{2}$ fraction increases $\left(I_{D} / I_{G}\right.$ is decrease), the cluster size decrease results in larger band gap which are in agreement to Robertson model [10]. At 523K ta-C:H thin films, the process need to stabilise $s p^{3}$ bonding and introduce larger disorder energy. This disorder energy is comparable to the stabilisation energy and forming larger cluster results in smaller band gap. At $573 \mathrm{~K}$, the degree of cross-linking of the $\mathrm{C}-\mathrm{C}$ network is increased leading to the larger cluster and decreased the optical gap further.

\subsection{Urbach Energy $\left(E_{0}\right)$}

The Urbach energy can be deduced from a plot of $\ln$ $\alpha$ versus photon energy, $h v$ as shown in Figure 5. The deviation of the straight line at low energies is due to the
Urbach behaviour. The straight line slope in this region is proportional to $1 / E_{o}$ and the calculated $E_{o}$ of the samples prepared at different substrate temperatures are shown in Table 2. It was found out that the Urbach energy, $E_{o}$ decreases with increasing substrate temperatures from $423 \mathrm{~K}$ to $573 \mathrm{~K}$ but the $E_{o}$ values increases as the substrate temperatures increase from 473 to $523 \mathrm{~K}$. The $E_{o}$ values for $423,473,523$ and $573 \mathrm{~K}$ substrate temperatures are 0.533 , $0.444,0.520$ and $0.384 \mathrm{eV}$, respectively.

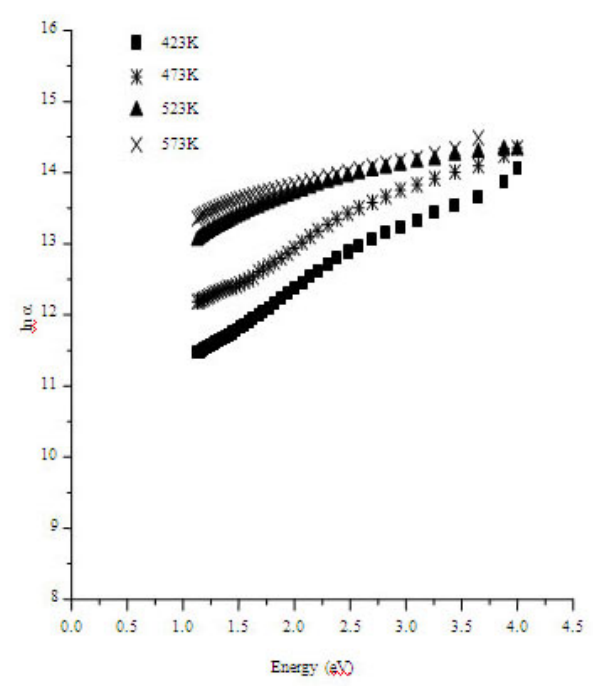

Figure 5: Urbach plot comparison graph

Table 2: The Urbach energy for taC:H thin films deposited at different substrate temperatures.

\begin{tabular}{cc}
\hline $\begin{array}{c}\text { Substrate } \\
\text { temperature }(\mathrm{K})\end{array}$ & $\begin{array}{c}\text { Urbach energy, } \\
E_{o}(\mathrm{eV})\end{array}$ \\
\hline 423 & 0.533 \\
473 & 0.444 \\
523 & 0.520 \\
573 & 0.384 \\
\hline
\end{tabular}

As mentioned above the Urbach energy, $E_{o}$ described the localized band tail states. Thus the decrease in $E_{o}$ from 0.533 to $0.444 \mathrm{eV}$ as the substrate temperature increases from 423 to $473 \mathrm{~K}$ describes the decrease of band tails. As the temperature increases to $523 \mathrm{~K}$, the $E_{o}$ is increased to $0.520 \mathrm{eV}$ because of the films are more disordered as the $\mathrm{H}$ in the film are starting to decrease and shown in IR studies. These hydrogen terminations in clusters can cause disorder to arise from bond length and bond angle distortions [11]. Urbach energy, $E_{o}$ decreases with decreasing hydrogen content. The decrease in $E_{o}$ may be due to more ordered structure with lower hydrogen concentration. Thus, at higher substrate temperature $(573 \mathrm{~K})$ the $E_{o}$ value is the lowest since hydrogen content in ta-C:H thin film is much lower and indicates that the film is becoming more ordered. 


\subsection{Photoluminescence}

One of the important characteristics of DLC thin films is it ability to exhibit strong room temperature photoluminescence (PL). The photoluminescence signal is an experimental technique that uses the photo excitation and de-excitation of carrier to determine the optical and structural properties of the materials. The de-excitation is determined by the recombination mechanism of the carrier. The recombination process in DLC films is influenced by the disorder which can bring allowable tail states within the gap, and by the defects states at the mid-gap. These defects in DLC are mostly due to the daggling bonds, which is originate from the clusters with odd numbered rings and form states closer to the Fermi level.

The PL analysis is carried out for the samples which are deposited at different substrate temperatures while other deposition parameter are fixed and its PL signals are shown in Figure 6. The PL bands with similar shape can be observed by using excitation energy of $3.5 \mathrm{eV}$ and its peak position practically remains the same down to $1.738 \mathrm{eV}$. The band becomes broader when substrate temperature is increased. For example, the $473 \mathrm{~K}$ is broader than $523 \mathrm{~K}$ substrate temperature.

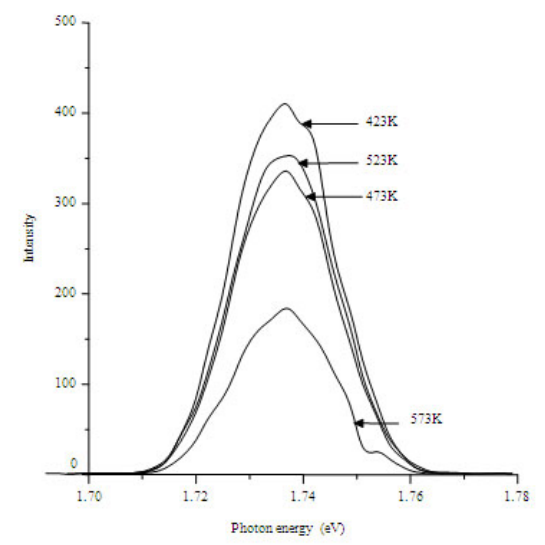

Figure 6: The photoluminescence spectra for the series of $\mathrm{taC} \cdot \mathrm{H}$ thin films deposited at different substrate temperature. The excitation energy was $\sim 3.5 \mathrm{eV}$

The emission band is centered at $1.738 \mathrm{eV}$. In this study, it does not observe a shift of the $1.738 \mathrm{eV}$ PL energy peak band but there was an increase in the intensity. This is attributed to a ta-C: $\mathrm{H}$ thin films associated recombination centre. The $1.738 \mathrm{eV}$ PL energy peak observed is consistent to that observed by Rusli et al.,[11]. The samples are deposited at difference substrate temperatures while other deposition parameters are fixed, so that no shift in the PL peak energy is observed. This is in agreement with [12], [13] and [14]. The PL peak energy observed is above the optical gap for all samples $(0.40-1.30 \mathrm{eV})$ but there is no clear relationship between the PL peak energy and the optical gap $[15,16]$.

The highest luminescence PL peak intensity is observed at $423 \mathrm{~K}$ and the lowest is at $573 \mathrm{~K}$ substrate temperature. It is observed that PL peak intensity decreases with increasing substrate temperature but the PL peak intensity for $523 \mathrm{~K}$ substrate temperature is slightly higher than $473 \mathrm{~K}$ peak intensity. The decrease of PL peak intensity with increasing substrate temperature is due to the increasing of non-radiative process and decrease in disorder of the sample. As the $\mathrm{C}-\mathrm{H}$ bonding is beginning to break at $523 \mathrm{~K}$, the sample becomes more disorder and results in an increase in luminescence intensity and this explains the slightly higher in peak intensity for $523 \mathrm{~K}$ substrate temperature compared to $423 \mathrm{~K}$. The hydrogen in DLC thin films promotes $s p^{3}$ fraction and also terminates the dangling bonds which normally produce non-radiative recombination. As ta$\mathrm{C}: \mathrm{H}$ contains low hydrogen, the degree of termination of dangling bond decrease results in an increase in nonradiative recombination process. The decrease in disorder of samples plus the increase of non radiative recombination process, result in the lowest PL peak intensity for the $573 \mathrm{~K}$ substrate temperature sample. This correlates well with Urbach energy obtained in section 3.3.

\section{CONCLUSION}

From the light transmission using UV-Vis spectroscopy it was found out that the optical transition changed from the allowed indirect transition to the forbidden direct transition as the substrate temperature increased. The photoluminescence study has shown that the recombination centre occurred at around $1.738 \mathrm{eV}$. The present work has also shown that the Urbach energy decreased with increasing of substrate temperature and this provides evidence that the DLC films have narrowed band tail. This decrease in Urbach energy was due to the more ordered structure with lower hydrogen concentration and larger cluster by the increase in the degree of cross-linking of the $\mathrm{C}-\mathrm{C}$ network. Distorted cluster which contribute to the broadening of the band tail may also contribute to the PL peak width. As the substrate temperature increased, the cluster size in the ta-C:H increased, resulting in smaller band gap and the structure was more ordered as the decrease in Urbach energy, decreased the in PL peak energy. The refractive index of the films depended on the film thickness as it increased with decreasing film thickness resulting from increasing substrate temperature. It can be concluded that substrate temperature has an obvious effect on the structural and optical properties of DLC thin films. As substrate temperature reached $573 \mathrm{~K}$, the not really ta$\mathrm{C}: \mathrm{H}$ thin films was converted to really ta-C:H thin films.

\section{ACKNOWLEDGEMENT}

We would like to acknowledge the financial supports from UTM under research grant IRGS, project number 78936, and the author also would like to thank Physics Department, Faculty of Science UTM for providing the measurement facilities. 


\section{REFERENCES}

[1] Werner M. and R Locher, Rep. Prog. Phys. 61(1998)1665

[2] Davis R. F. (Ed.), Diamond Films and Coatings, William Andrew Publishing, Noyes, 1993.

[3] Silinskas M., A. Grigonis, V. Kulikauskas and I. Manika, Thin Solid Films, 516(2008)1683-1692

[4] Gupta, P., Singh, V. and Meletis, E.I., Tribology International. 37(2004)1019-1029.

[5] Staryga E. and G. W. Bąk, Diamond and Related Materials, 14(2005) 23-34

[6] Smith, D. L., 1995, Thin film Deposition: Principles and Practice, McGraw-Hill, Boston.

[7] Bewilogun, K., Wittorf, R., Thomsen, H., Weber, M., Thin Solid Films. 447-448 (2004)142-147.

[8] Tauc, J., in Optical Properties of Solids, Abeles, F., Editors, North-Holland, Amsterdam, (1970).

[9] Weiler, M., Sattel, S., Giessen, T., Jung, K. and Ehrhardt, H., Physical Review B. 53(3) (1996)1594-1608

[10] Robertson, J., Diamond and Related Materials. 12(2003)79-84.

[11] Manage, D.P., Structural and Optical Characterization of Hydrogenated Amorphous Carbon Thin Films. University of Toronto: Ph. D. Thesis, (1998).

[12] Rusli, Gehan, Amaratunga, A.J. and Silva, S.R.P., Thin Solid Films. 270(1995)160-164

[13] Koos, M., Pocsik, I., Erostyak, J. and Buzadi, Journal of Non-Crystalline Solids. 227-230(1998)579-582.

[14] Anguita, J.V., Young, W.T., Khan, R.U., Silva, S.R.P., Haq, S., Sturland, I. and Pritchard A., Journal of Non-Crystalline Solids. 266269(2000)821-824.

[15] Fule, M., Toth, S., Veres, M., Pocsik, I. and Koos, M., Diamond and Related Materials. 14(2005)1041-1046.

[16] Toth, S., Veres, M., Fule, M. and Koos, M., Diamond and Related Materials. 15(2006)967-971. 